\title{
DEVELOPMENT OF A NEW ALLOY FOR DIRECTIONAL SOLIDIFICATION OF LARGE INDUSTRIAL GAS TURBINE BLADES
}

\author{
R. Bürgel ${ }^{1}$, J. Grossmann ${ }^{2}$, O. Lüsebrink ${ }^{2}$, \\ H. Mughrabi ${ }^{3}$, F. Pyczak ${ }^{3}$, R.F. Singer ${ }^{4}$, A. Volek ${ }^{4}$ \\ ${ }^{1}$ University of Applied Sciences, Faculty of Engineering and Computer Sciences, Albrechtstr. 30, D-49076 Osnabrück \\ ${ }^{2}$ Doncasters Precision Castings-Bochum GmbH, P.O. Box 1025 50, D-44725 Bochum \\ ${ }^{3}$ University of Erlangen-Nürnberg, Dept. of Materials Science and Engineering, Institute I, Martensstr. 5, D-91058 Erlangen \\ ${ }^{4}$ University of Erlangen-Nürnberg, Dept. of Materials Science and Engineering, Institute II, Martensstr. 5, D-91058 Erlangen
}

Keywords: Nickel-base superalloy, directional solidification, industrial gas turbine, rhenium, cobalt, phase stability, stress-rupture, hot corrosion

\begin{abstract}
A nickel-base superalloy for directional solidification (DS) of industrial gas turbine blades was developed based on alloy IN792 with approximately 12 mass \% Cr. From preliminary test results a temperature gain in stress-rupture strength of $30 \mathrm{~K}$ can be expected compared to Re-free aero engine alloys with columnar grains. This significant strength improvement can be achieved by adding 2 to 3 mass $\% \mathrm{Re}$ in the group of 12 mass $\% \mathrm{Cr}$ alloys. With balanced $\mathrm{Cr}-, \mathrm{Al}-$, and Ti- contents they also exhibit superior hot corrosion resistance compared to typical high $\mathrm{Al} /$ low $\mathrm{Cr} /$ low $\mathrm{Ti}$ aero engine alloys. The castability for large blades was proved.
\end{abstract}

\section{Introduction}

For industrial gas turbine (IGT) blade materials the requirements regarding creep strength and hot corrosion resistance might come into conflict. To increase the strength of IGT alloys, one would have to make use of typical aero engine materials with low $\mathrm{Cr}$ $(<10 \%)$, low $\mathrm{Ti}(<1 \%)$, and high $\mathrm{Al}(>5 \%)$ content along with Re-additions (approx. $3 \%$ ). All contents are stated in mass \%. Such alloys exhibit high creep resistance due to particle strengthening by a high fraction of the coherent and thermally relatively stable $\gamma^{\prime}$-phase and high solid solution strengthening, primarily owing to $\mathrm{W}$ and Re. The Cr-content has to be kept low because otherwise these alloys would become unstable. This means that embrittling topologically closed-packed (TCP) phases such as the tetragonal body-centered $\sigma$-phase and/or the orthorhombic Pphase (in some Re-containing alloys) would precipitate.

The oxidation resistance of high $\mathrm{Al}$ aero engine alloys is good because of alumina scale formation. However, their hot corrosion behavior is generally poor since no solid sulfides will form if sulfur penetrates into the bulk. The only sulfide type that is solid in the temperature range considered is $\mathrm{Cr} / \mathrm{Ti}$-sulfide.

If the IGT is operated at very high temperatures and if it burns clean fuel in a lowly contaminated environment, the conditions are similar to the ones for aero engines and the alloys described above will do the job. An appropriate coating, usually of the MCrAlY overlay type, will ensure safe service operation for the envisaged overhaul periods.
The situation changes if the above mentioned conditions are not fulfilled, i.e. if typical hot corrosion phenomena are encountered. This is the case if particularly higher amounts of sulfur enter the turbine through contaminated fuel and/or inlet air. Even if the temperatures in the front stage would be high enough for oxidation to dominate, the blade materials in the following stages would suffer from type I sulfidation, i.e. the type of attack between about $800^{\circ} \mathrm{C}$ and $1000{ }^{\circ} \mathrm{C}$, or even type II hot corrosion below about $800{ }^{\circ} \mathrm{C}$.

The aim of the present joint project was to develop a new blade alloy which exhibits as high oxidation and hot corrosion resistance as high chromium IGT materials, such as IN792 $(12.5 \% \mathrm{Cr}$, $3.5 \% \mathrm{Al}, 3.9 \% \mathrm{Ti}$ ), but at a creep strength level comparable to Re-free aero engine blade alloys, e.g. CM247LC $(8.1 \% \mathrm{Cr}$, $5.6 \% \mathrm{Al}, 0.7 \% \mathrm{Ti}$ ). The new alloy should be suitable for directional solidification (DS) with a columnar grain structure. Such anisotropic structures are state-of-the-art in modern jet engines as well as in IGTs to enhance thermal fatigue and creep strength.

While Re is a very effective solid solution strengthener in aero engine blade materials, no similar Re-containing IGT alloys with $>10 \% \mathrm{Cr}$ are known in the open literature. This opened a gap for further investigations.

\section{Experimental}

Alloys

Altogether, 30 compositional modifications based on alloy $D S$ IN792 were defined and tested. The alloys did not contain any Hf, since $\mathrm{Hf}$ promotes the formation of $\gamma / \gamma^{\prime}$-eutectic and hence lowers the incipient melting temperature. Furthermore, Hf causes mould reactions particularly at long casting cycles for large IGT-components.

Elements increasing the $\gamma^{\prime}$-volume fraction or improving solid solution strengthening were modified systematically. Re-additions were examined up to $3 \%$. The Co-content was varied and also non-standard alloying elements such as $\mathrm{Ru}, \mathrm{Ir}, \mathrm{Pt}$, and $\mathrm{Pd}$ were tested (each up to $3 \%$ ). Finally, a preferred alloy (ExAl7) was optimized by fine-tuning of the chemical composition and by 
improvement of the heat treatment procedure. Table 1 shows its chemical composition along with comparable alloys.

Table 1: Chemical composition of the developed preferred alloy compared to standard alloys

\begin{tabular}{|c|l|l|l|l|l|l|l|c|}
\hline & $\mathrm{Cr}$ & $\mathrm{Co}$ & $\mathrm{Mo}$ & $\mathrm{W}$ & $\mathrm{Ta}$ & $\mathrm{Al}$ & $\mathrm{Ti}$ & $\mathrm{Re}$ \\
\hline ExAl7 & 12.0 & 9.0 & 1.8 & 3.5 & 4.0 & 3.4 & 3.9 & $2-3$ \\
\hline DS-IN792 & 12.5 & 9.0 & 1.9 & 4.0 & 4.0 & 3.5 & 3.9 & - \\
\hline CM247LC & 8.1 & 9.2 & 0.5 & 9.5 & 3.2 & 5.6 & 0.7 & - \\
\hline
\end{tabular}

Casting of specimens and blades

$100 \mathrm{~kg}$ master melts were produced in an industrial scale vacuum induction furnace. Directionally solidified rods and slabs were cast of all investigated alloys in a small SX-/DS-vacuum furnace and machined as test pieces. For the preferred alloy ExAl7 the directional solidification casting process was developed using an IGT blade with a length larger than $400 \mathrm{~mm}$ and a weight of more than $10 \mathrm{~kg}$.

\section{Heat treatment}

For the development of appropriate solution and homogenization heat treatments of each alloy a small chamber furnace with $\mathrm{MoSi}_{2}$ heating elements operating in air was used. The optimum parameters found on laboratory scale were transferred to a large scale vacuum production furnace by comparing the resulting microstructures. Finally, all alloys were precipitation hardened in two steps $\left(1080^{\circ} \mathrm{C} / 4 \mathrm{~h}+845^{\circ} \mathrm{C} / 24 \mathrm{~h}\right)$ before further testing.

\section{Mechanical testing}

Besides tensile tests at ambient as well as at elevated temperatures, stress-rupture tests were conducted with all alloy variants. The specimens of the preferred alloy modification ExAl7 were tested in the temperature range from $700{ }^{\circ} \mathrm{C}$ to $950{ }^{\circ} \mathrm{C}$ and for test times between $327 \mathrm{~h}$ and in excess of $12,500 \mathrm{~h}$. Strain was monitored either continuously or in interrupted tests with multispecimen devices. Thus, times to $0.2 \%, 0.5 \%$, and $1 \%$ creep strain and times to rupture were recorded precisely.

\section{Corrosion testing}

Oxidation in air was tested at $1000{ }^{\circ} \mathrm{C}$ for $300 \mathrm{~h}, 1000 \mathrm{~h}$, and $3000 \mathrm{~h}$. Type I hot corrosion was simulated in an artificial slag at $900{ }^{\circ} \mathrm{C}$ for $300 \mathrm{~h}, 1000 \mathrm{~h}$, and $2000 \mathrm{~h}$. This corrosive ash contains various sulfates and oxides which are typically found as industrial gas turbine blade deposits. In both cases the depth of corrosive attack was measured metallographically.

\section{Metallographic techniques}

Polished samples were etched with the so-called Mo-reagent consisting of $100 \mathrm{ml} \mathrm{H}_{2} \mathrm{O}, 100 \mathrm{ml} \mathrm{HNO}, 100 \mathrm{ml} \mathrm{HCl}$, and $6 \mathrm{~g}$ $\mathrm{MoO}_{3}$ (Mo-acid). This chemical etchant takes the $\gamma^{\prime}$-phase into solution. In cases in which it was doubtful whether the $\gamma^{\prime}$-phase had been dissolved by etching or in which holes had been produced due to incipient melting, particularly in eutectic areas, an electrochemical etching of the $\gamma$-matrix was employed using oxalic acid $\left[10 \mathrm{~g}(\mathrm{COOH})_{2}\right.$ dissolved in $\left.90 \mathrm{ml} \mathrm{H}_{2} \mathrm{O}\right]$.

For transmission electron microscope (TEM) investigations thin foils were prepared by electrochemical thinning. No significant thickness differences between $\gamma$-matrix and $\gamma^{\prime}$-precipitates were found.
Determination of the segregation coefficient

The degree of homogenization was determined by measuring the chemical composition locally in dendrite cores and in the center of interdendritic regions. The measurements were carried out in areas of $10 \mu \mathrm{m} \times 10 \mu \mathrm{m}$ size using a scanning electron microscope equipped with EDS devices. At least five measurements were taken in each microstructural region and the mean value was calculated. The segregation coefficient $\mathrm{k}^{\text {seg }}$ is defined as follows:

$$
\mathrm{k}^{\mathrm{seg}}=\frac{\mathrm{c}_{\mathrm{dc}}}{\mathrm{c}_{\mathrm{id}}}
$$

where $c_{\mathrm{dc}}$ : concentration of the respective element in the dendrite core

$c_{i d}$ : concentration of the respective element in the interdendritic region.

Determination of the $\gamma^{\prime} / \gamma$-partitioning coefficient To determine the partitioning behavior of the different alloying elements between $\gamma^{\prime}$-precipitates and $\gamma$-matrix, the chemical compositions of both phases were measured by EDS in the TEM. The partitioning coefficients $\mathrm{k}^{\gamma^{\prime} / \gamma}$ were calculated according to:

$$
\mathrm{k}^{\gamma^{\prime} / \gamma}=\frac{\mathrm{c}^{\gamma^{\prime}}}{\mathrm{c}^{\gamma}}
$$

\footnotetext{
where $c^{\gamma^{\prime}}$ : concentration of the respective element in $\gamma^{\prime}$

$c^{\gamma}:$ concentration of the respective element in $\gamma$.
}

\section{Results}

Castability

Besides visual inspection of the DS grain structure, all specimens and blades were checked for grain boundary cracking by means of FPI (Fluorescent Penetrant Inspection). While rods and slabs did not cause casting problems, for crack-free columnar solidification of large and hollow IGT-blades a careful control of minor elements was essential (which is out of the scope of the present paper). For the preferred alloy ExAl7 the casting technique was developed successfully, while comparative casting trials with the same blade made of DS-IN792 still revealed a tendency towards grain boundary cracking.

Heat treatments

One demanding task was to develop an appropriate solution heat treatment for each investigated alloy. The objective was to take all the dendritic and interdendritic $\gamma^{\prime}$-precipitates as well as most of the $\gamma / \gamma^{\prime}$-eutectic into solution, while avoiding incipient melting in eutectic regions.

It was found that all alloy variants with $>8 \%$ Co could be fully solution treated at a single temperature step of either $1220^{\circ} \mathrm{C}$, $1240{ }^{\circ} \mathrm{C}$, or $1260^{\circ} \mathrm{C}$ for $4 \mathrm{~h}$, depending on the alloy composition. 
Unexpected difficulties arose with zero or low Co-alloy variants. These alloys either reveal too high residual eutectic or even incipient melting after the above mentioned single-step solution treating. Very lengthy multi-step heat treatments with annealing times exceeding $30 \mathrm{~h}$ in some cases became necessary in order to avoid an undesirable microstructure such as the example shown in Fig. 1. Additionally, the alloy variants with zero or low Co exhibit a degenerated $\gamma^{\prime}$-morphology after complete heat treatment except one variant containing $5 \% \operatorname{Re}$ (see below)

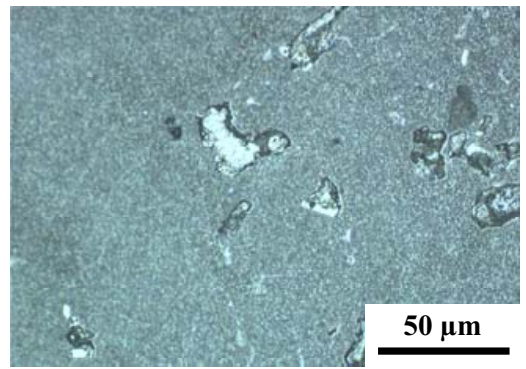

Figure 1: Undesirable microstructure of a zero Co-alloy, not yet homogenized after four annealing steps of in total about $13 \mathrm{~h}$ between $1235^{\circ} \mathrm{C}$ and $1255^{\circ} \mathrm{C}$ : Incipient melting of residual eutectic has occurred.

For the preferred alloy ExAl7 a solution heat treatment lasting $4 \mathrm{~h}$ at $1240{ }^{\circ} \mathrm{C}$ allowed to fully solve $\gamma^{\prime}$ and the eutectic without any incipient melting. However, clear differences between dendritic and interdendritic regions with respect to inhomogeneous element distribution remain. Primarily $\mathrm{W}$ and Re are enriched in dendritic areas leading to phase instabilities in these regions. Therefore, a homogenization heat treatment was developed in order to reduce these segregations as far as possible. Based on the $1240^{\circ} \mathrm{C}$ solution-treating step, further steps were added up to $1267^{\circ} \mathrm{C}$ without producing local melting.

With a second batch of ExAl7 a further optimized solution and homogenization heat treatment was applied that represents a good compromise between homogenization and annealing costs. Most of the specimens that are included in the stress-rupture diagram shown below received the optimized treatment.

\section{$\gamma^{\prime}$-microstructure}

By evaluating SEM-micrographs, $\gamma^{\prime}$-volume fractions between $40 \%$ to $50 \%$ were measured for all alloys.

The $\gamma^{\prime}$-microstructure in the fully heat-treated condition show a cuboidal precipitate shape for all alloys with a Co-content of $9 \%$, Fig. 2a. At lower Co-contents the shape of the $\gamma^{\prime}$-precipitates changes from cuboidal to butterfly-like as shown in Fig. 2 b.

It was found that these unusual precipitate shapes already develop during standard cooling from solution treating. Subsequently water-quenched samples, in contrast, reveal mostly the normal cuboidal $\gamma^{\prime}$-morphology after $1080{ }^{\circ} \mathrm{C}$ aging. Further, it was found that the uppermost $20^{\circ} \mathrm{C}$ of cooling from full solution-treating temperature are critical for the development of the $\gamma^{\prime}$-microstructure.
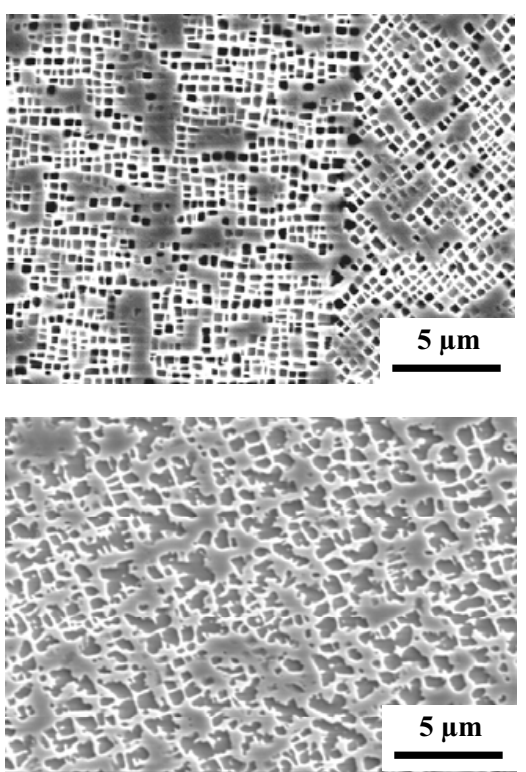

Figure 2: a) Example of the cuboidal $\gamma^{\prime}$-particle shape found in the 9 wt-\% Co-alloy variant ExAl7; b) degenerated $\gamma^{\prime}-$ morphology of a zero Co-alloy variant after complete heat treatment

The $\gamma^{\prime}$-microstructure in the Re-containing alloys differs in some aspects from that found in the Re-free alloys. The precipitate size in the dendritic cores is measurably smaller than in the interdendritic regions. These differences, which are recognizable in the SEM-micrograph of ExAl7 in Fig. 3, remain even after prolonged high temperature annealing at $1000{ }^{\circ} \mathrm{C}$. To minimize or remove this effect an optimized heat treatment was developed which results in a more homogeneous distribution of alloying elements between dendritic cores and interdendritic regions (see also Heat treatment).

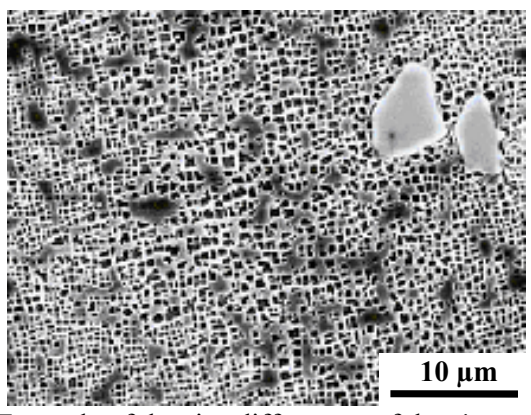

Figure 3: Example of the size differences of the $\gamma^{\prime}$-precipitates in the dendritic cores and the interdendritic regions in the Re-containing alloy ExAl7

In the alloys with Co-contents less than approximately $9 \%$ the tendency of the $\gamma^{\prime}$-precipitates to develop a butterfly-like shape is much less pronounced if $\mathrm{Re}$ is present in higher concentration in the alloy composition. For example, one alloy containing $0 \% \mathrm{Co}$ and $3 \%$ Re shows butterfly-shaped $\gamma^{\prime}$-precipitates, while the same alloy with $5 \%$ Re precipitates cuboidal $\gamma^{\prime}$. 
All alloys investigated in this project develop a pronounced directionally coarsened or rafted $\gamma^{\prime}$-microstructure during high temperature deformation. The orientation of the $\gamma^{\prime}$-rafts is perpendicular to the stress axis under external tensile loads and parallel to the stress axis under external compressive loads, indicating that all alloys have a negative lattice misfit at the deformation temperature (N-type, see Fig. 4). In Re-containing alloys without optimized heat treatment the rafting observed in the dendritic cores was more pronounced than in the interdendritic regions.
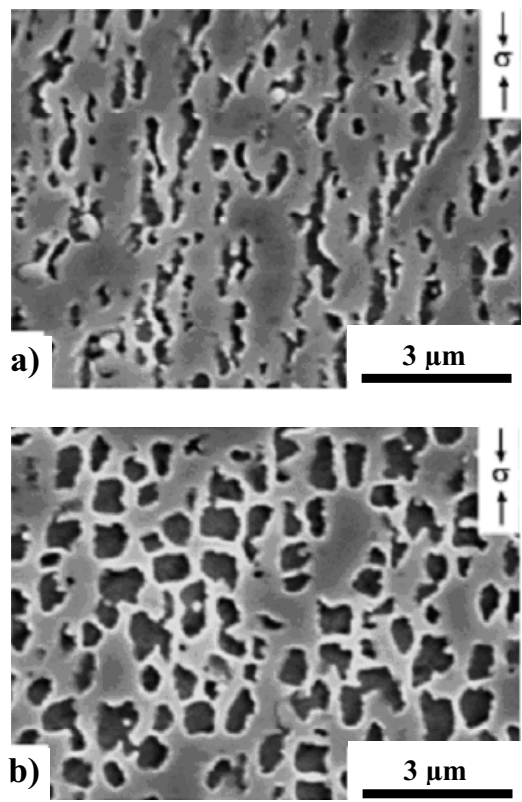

Figure 4: Examples of differently rafted regions in the Recontaining alloy ExAl7 after creep deformation, Re segregation between (a) dendritic cores and (b) interdendritic regions The axis of stress $\sigma$ is indicated.

The lattice parameters of $\gamma$ and $\gamma^{\prime}$ are also influenced by the contents of different alloying elements. This can be illustrated by comparing the lattice constants of DS-IN792 and the preferred alloy ExAl7 measured with X-ray diffraction. While both exhibit nearly equal $\gamma^{\prime}$-lattice parameters of $0.3593 \mathrm{~nm}$ for DS-IN792 and $0.3592 \mathrm{~nm}$ for ExAl7, respectively, the $\gamma$-matrix lattice constant of ExAl7 is increased to $0.3594 \mathrm{~nm}$ compared to $0.3591 \mathrm{~nm}$ measured for DS-IN792 [1].

\section{TCP-phase formation}

In some of the alloys so-called topologically closed packed (TCP) phases precipitate during elongated exposure at high temperatures. In a number of alloys TCP-phases are already present in the fully heat-treated condition. The TCP-phases encountered in the Recontaining alloys differ in certain aspects from the ones in the Refree alloys. Examples of both types of TCP-phases are shown in Fig. 5 a) and b).

Both types of TCP-phases have a needle- or plate-like shape with a width of about $100 \mathrm{~nm}$. While the ones found in the fully heattreated condition of Re-containing alloys have a length of some micrometers, TCP-phases with a length exceeding some hundred micrometers are found in Re-free alloys. These differences in size remain after high-temperature exposure [2].
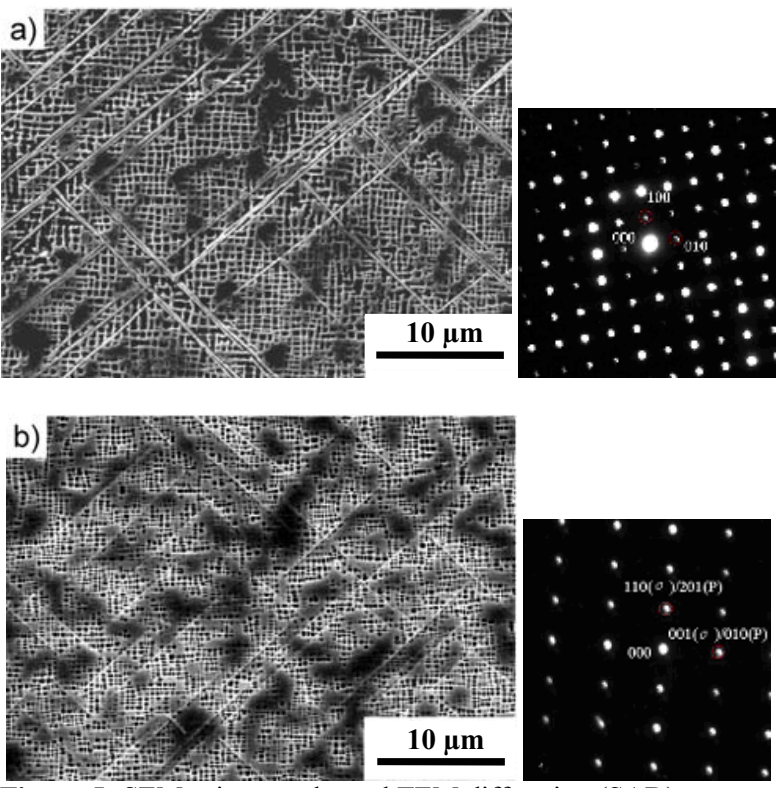

Figure 5: SEM-micrographs and TEM diffraction (SAD)patterns of different kinds of TCP-phases: a) Re-free $\sigma$-phase, b) Re-containing $\sigma$ - or P-phase

Table 2: Chemical composition of the Re-free and Recontaining type of TCP-phase in the alloy ExAl3 and ExAl7 Contents of each element are given in at.\% determined by EDSmeasurements in the TEM.

\begin{tabular}{|c|c|c|c|c|c|c|}
\hline & $\mathrm{Cr}$ & $\mathrm{Co}$ & $\mathrm{Ni}$ & $\mathrm{W}$ & $\mathrm{Mo}$ & $\mathrm{Re}$ \\
\hline Without Re & 32.4 & 11.8 & 23.0 & 20.3 & 12.6 & - \\
\hline With Re & 18.8 & 5.0 & 10.0 & 29.1 & 8.4 & 26.6 \\
\hline
\end{tabular}

The chemical compositions of the TCP-phases were measured by EDS in the TEM (Tab. 2).

In the alloys containing Re, this element is enriched in the TCPphase while the Cr-level is equal to the one measured in the $\gamma$ matrix. In contrast, the TCP-phases in the Re-free alloys have a strongly increased amount of $\mathrm{Cr}$ compared with the $\gamma$-matrix composition. Other refractory elements such as $\mathrm{W}$ and Mo have similar levels in both kinds of TCP-phase. An identification of the type of TCP-phase based on the chemical composition is not possible, because Re-containing TCP-phases of $\sigma$ - and P-type are reported to have nearly identical chemical compositions [3]. The nominal base formula of the P-phase is $\mathrm{Cr}_{18} \mathrm{Mo}_{42} \mathrm{Ni}_{40}$ but broad substitution is possible as for the $\sigma$-phase (nominally $\mathrm{FeCr}$ ).

To overcome this problem in the identification of the TCP-phases, electron diffraction patterns recorded in the TEM were used to determine the lattice cells of the TCP-phases (see Fig. 5). The crystal structure of the TCP-phase was determined to be of the $\sigma$ type in the case of the Re-free phase. For the Re-containing TCPphase, the identification of the lattice structure was ambiguous and the crystal structure can either be of $\sigma$ - or P-type. Both types, $\mathrm{P}$ and $\sigma$, are reported in Re-containing alloys [3, 4]. 
Furthermore, TCP-phase formation in the Re-containing alloys is limited to dendrite cores and arms (Fig. 6) [2]. This is caused by microsegregation which is still existing even after homogenization due to the low diffusivity of Re. This was proved for alloy ExAl7. While in the standard heat treated condition TCP-phase precipitation was already initiated after $200 \mathrm{~h}$ at $800^{\circ} \mathrm{C}$, in the homogenized version TCP-phase formation could hardly be detected by examining a sample which was tested for $4896 \mathrm{~h}$ at $850^{\circ} \mathrm{C}$.

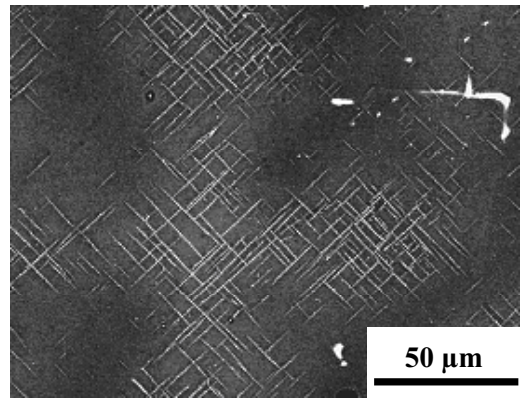

Figure 6: Dendritic precipitation of TCP-phases in a Recontaining alloy after $500 \mathrm{~h}$ aging at $800{ }^{\circ} \mathrm{C}$

The degree of homogenization was determined by measuring the segregation coefficient $\mathrm{k}^{\mathrm{seg}}$. For alloy ExAl7 in the as-cast condition $\mathrm{a} \mathrm{k}^{\text {seg }}$ value for $\mathrm{Re}$ of about 2.2 was measured, after $1240{ }^{\circ} \mathrm{C} / 4 \mathrm{~h} \mathrm{k}{ }^{\text {seg }} \approx 1.8$ was found and after homogenization annealing $\mathrm{k}^{\mathrm{seg}}$ has decreased to about 1.2. The latter microstructure is shown in Fig. 7.

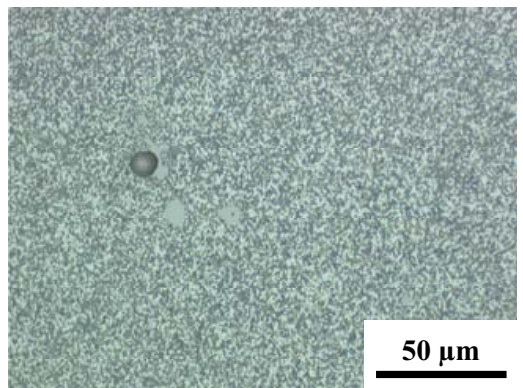

Figure 7: Homogenized Re-containing alloy ExAl7 without TCPphase formation

Simple electron vacancy $\left(N_{v}\right)$ number calculations to determine the phase stability of the alloy composition were performed based upon algorithms developed by [5]. For each alloy the average electron vacancy number $N_{v}$ was calculated. Results for selected experimental alloys are listed in Tab. 3 in the order of increasing $N_{v}$ number together with the investigated time and temperature range.

It can be seen that in Re-free alloys $N_{v}$ calculations and microstructural results show good agreement. The critical $N_{v}$ number indicating phase instability is found to be within the range $2,49<N_{v, c}<2,56$. In the Re-containing alloys the microstructural evaluation revealed no correlation between $N_{v}$ number and the alloys' susceptibility to TCP-phase formation.
Table 3: Calculated average $N_{v}$ numbers for different alloys

The investigated time and temperature intervals are given, too.

\begin{tabular}{|c|c|c|c|c|c|}
\hline & & $N_{v}$ & $\begin{array}{c}\text { Time } \\
\text { range }[\mathrm{h}]\end{array}$ & $\begin{array}{l}\text { Temperature } \\
\text { range }\left[{ }^{\circ} \mathrm{C}\right]\end{array}$ & TCP \\
\hline \multirow{9}{*}{$\begin{array}{l}\stackrel{\Xi}{\rightleftarrows} \\
\simeq\end{array}$} & \multirow{9}{*}{ 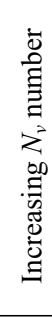 } & 2,38 & 1697 & $800-950$ & no \\
\hline & & 2,39 & 500 & $800-950$ & no \\
\hline & & 2,49 & 3180 & $800-1000$ & no \\
\hline & & 2,56 & 500 & $800-950$ & yes \\
\hline & & 2,61 & 4525 & $750-1000$ & yes \\
\hline & & 2,78 & 500 & $800-980$ & yes \\
\hline & & 2,81 & 710 & $800-980$ & yes \\
\hline & & 2,81 & 1278 & $800-980$ & yes \\
\hline & & 2,90 & 500 & $800-980$ & yes \\
\hline \multirow{10}{*}{ 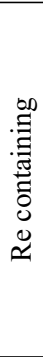 } & \multirow{10}{*}{ 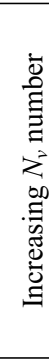 } & 2,15 & 1996 & $800-950$ & no \\
\hline & & 2,25 & 5632 & $800-950$ & yes \\
\hline & & 2,25 & 500 & $800-950$ & no \\
\hline & & 2,27 & 3447 & $800-950$ & no \\
\hline & & 2,30 & 4896 & $750-1000$ & yes \\
\hline & & 2,33 & 3988 & $800-950$ & no \\
\hline & & 2,36 & 500 & 800 & no \\
\hline & & 2,44 & 500 & 800 & yes \\
\hline & & 2,50 & 1000 & $800-1000$ & yes \\
\hline & & 2,51 & 1000 & $800-1000$ & yes \\
\hline
\end{tabular}

Partitioning behavior of alloying elements

Based on the DS-IN792 alloy composition two experimental alloys containing $\mathrm{Re}+\mathrm{Ru}$ and $\mathrm{Re}+\mathrm{Ir}$ were produced. After the standard heat treatment, the $\gamma$ - and $\gamma^{\prime}$-compositions were measured using EDS analysis equipment attached to TEM-microscopes in the scanning mode.

The results are shown in Fig. 8 [6]. The gray bars indicate the range of the values for each element found in the literature $[7,8$, $9,10,11]$. The main solid solution strengtheners $\mathrm{W}, \mathrm{Mo}$, and particularly Re are enriched in the $\gamma$-matrix. Ru also partitions to $\gamma$, while Ir is evenly distributed between $\gamma$ and $\gamma^{\prime}$. This is in good agreement with measurements carried out by Yokokawa et al. [12].

However, both $\mathrm{Ru}$ and Ir do not influence the partitioning behavior of the other refractory elements $\mathrm{W}, \mathrm{Mo}$, and Re, which is in contradiction to published results [13].

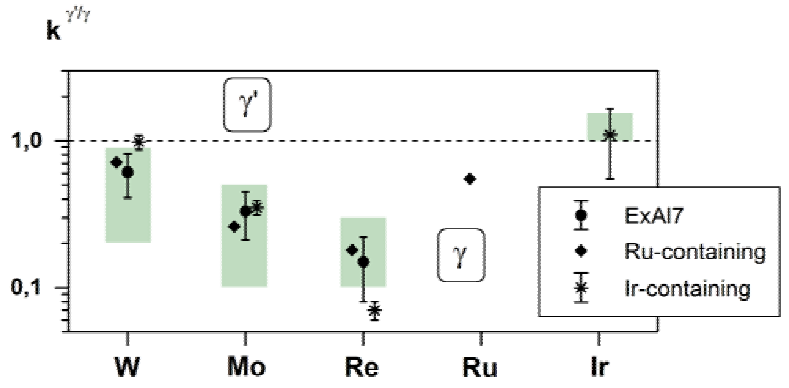

Figure 8: $\gamma^{\prime} / \gamma$-distribution for different elements in the investigated alloys (Gray bars indicate the range of $\mathrm{k}^{\gamma^{\prime} / \gamma}$ values found in the literature.) 
Mechanical properties

Creep strength is of primary interest in the development of a new high-temperature alloy, because it influences the stress-rupture life as well as stress relaxation and thermal fatigue resistance.

For the preferred alloy variant ExAl7 a total test time of about $115,000 \mathrm{~h}$ has been accumulated. Four specimens have endured test times in excess of $10,000 \mathrm{~h}$, and these four have not yet ruptured. Fig. 9 demonstrates the stress-rupture potential of the new alloy ExAl7 in comparison to DS-IN792 and DS-CM247LC in a Larson-Miller-plot. This diagram is actually based on 21 specimens of ExAl7 of which 9 have not yet broken. Especially in the range of LMP $>28 \cdot 10^{3}$, i.e. at higher temperatures and longer times, the results are preliminary, because tests are still running and have exceeded about $8000 \mathrm{~h}$ already. Thus, the improvement compared to the other two alloys will increase further. From the results obtained until now a temperature gain of approximately $30 \mathrm{~K}$ is estimated compared to the data available for the reference alloy $D S-C M 247 L C$.

The influence of a homogenization heat treatment described above was spot-checked and resulted in an increase of $18 \%$ in time to rupture under equivalent test parameters. Occasionally, very small dendritic and interdendritic TCP-precipitates were detected after the test time of $4896 \mathrm{~h}$ at $850{ }^{\circ} \mathrm{C}$ for the homogenized condition (see section TCP-phase formation).

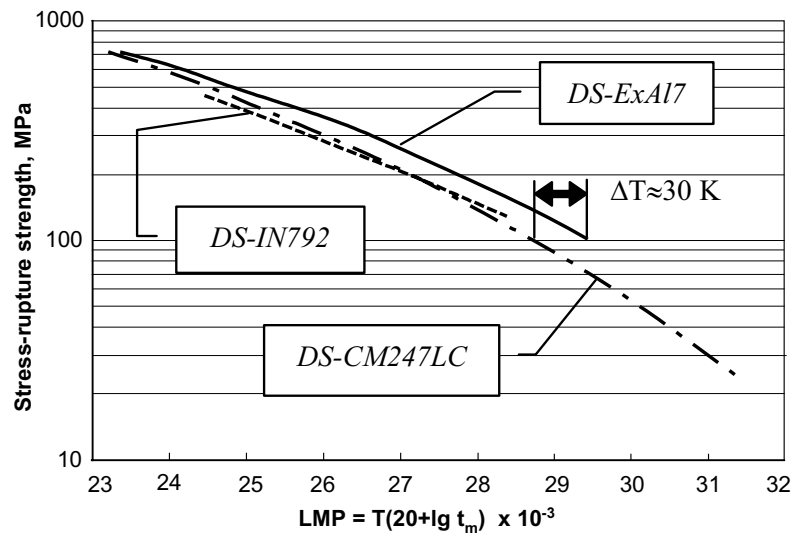

Figure 9: Larson-Miller plot for stress-rupture data in the longitudinal direction ( $\mathrm{T}$ in $\mathrm{K}$ and $\mathrm{t}_{\mathrm{m}}$ in $\mathrm{h}$ )

Oxidation and hot corrosion

The group of alloys with Al-contents of $5.5 \%$ up to $6 \%$ exhibits the lowest attack under oxidizing conditions in air. All other experimental alloys with $\mathrm{Al}$-contents between $3.2 \%$ and $3.9 \%$ show a little higher depth of oxidation. They all lie within the same typical range of scatter for such tests.

The type I hot corrosion simulation at $900{ }^{\circ} \mathrm{C}$ gave interesting results. After $300 \mathrm{~h}$ exposure the high Al-group of alloys is attacked least of all. However, after $1000 \mathrm{~h}$, these alloys exhibit catastrophic attack with formation of liquid phases detectable in the microstructure, Fig. 10. All experimental alloys with approximately $12 \% \mathrm{Cr}$, less than $4 \% \mathrm{Al}$ and $3.5-4 \% \mathrm{Ti}$ reveal roughly the same good resistance under these test conditions without formation of molten corrosion products after the longest test time of 2000 h, Fig. 11. Some high Al/low Cr/low Ti aero engine alloys which were tested for the sake of comparison also fail by catastrophic attack under these test conditions.

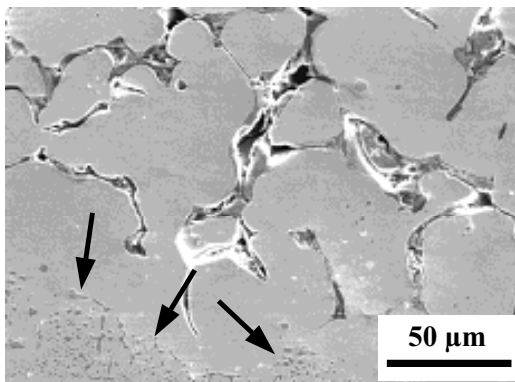

Figure 10: Hot corrosion attack of an alloy with $12 \% \mathrm{Cr}, 5.5 \%$ $\mathrm{Al}$, and $2 \%$ Ti after $900{ }^{\circ} \mathrm{C} / 1000 \mathrm{~h}$

The striking dark large areas were liquid at test temperature. At the corrosion front (bottom left, see arrows) solid $\mathrm{Cr} / \mathrm{Ti}$-sulfides are visible.

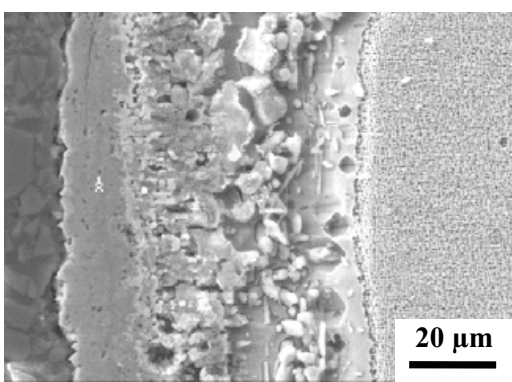

Figure 11: Hot corrosion attack of an alloy with $12 \% \mathrm{Cr}, 3.5 \%$ $\mathrm{Al}$, and $3.9 \% \mathrm{Ti}$ after $900{ }^{\circ} \mathrm{C} / 2000 \mathrm{~h}$

Oxides and solid $\mathrm{Cr}$ /Ti-sulfides have formed.

\section{Discussion}

Effects of cobalt

Interesting results were obtained by varying the Co-content. The role of this major alloying element in nickel-base superalloys is somewhat dubious (see for instance [14]). Only few commercial alloys exist with less than approximately $9 \%$ Co (e.g. IN713 with $0 \%, S R R 99$ and CMSX-6 with $5 \%$, René N4 and René N5 with $7.5 \%$, respectively).

Co is known to improve the creep resistance at intermediate temperatures, because it lowers the stacking fault energy of the alloy. It can be assumed that this effect will play a minor role in the high temperature regime. Murakami et al. [15] report, that Co is not always essential for practical use, since Co-containing alloys are very sensitive to tensile orientation. Therefore, the development of Co-free alloys was recommended.

A strong solid solution strengthening effect should not be expected by the element Co at very high temperatures, and also its influence on the amount of $\gamma^{\prime}$ at service temperature should be negligible. Considering phase stability, the decrease of Co content in an alloy promises a beneficial effect because the $\mathrm{N}_{\mathrm{v}}$ number of Co (1.61) is higher than the $\mathrm{N}_{\mathrm{v}}$ number of $\mathrm{Ni}(0.66)$. In this work the validity of this assumption was confirmed. For instance, a 
reduction of Co from $4 \%$ to $0 \%$ leads to a decrease of the average $N_{v}$-number by 0.17 . This comes along with the experimental finding that, in the investigated time and temperature regime, the Co-free alloy has a stable microstructure with respect to TCPphase formation, while the alloy with $4 \%$ Co has not. Considering these aspects, a reduction of Co seems recommendable for an alloy development program.

However, it is well-known that by reducing the Co-content the $\gamma^{\prime}$ solvus temperature increases [e.g. 16, 17, 18, 19]. The reason obviously is that Co increases the solubility of $\mathrm{Al}$ and possibly also of Ta [20] in the $\gamma$-Ni-solid solution matrix, i.e. if Co is reduced the $\left(\gamma+\gamma^{\prime}\right)$ phase field is enlarged and expanded towards higher temperatures. This was clearly confirmed in the present investigation. It was also found that incipient melting of the $\gamma / \gamma^{\prime}$ eutectic occurs at a lower temperature without Co or with reduced Co. With the aim to take both the dendritic and interdendritic $\gamma^{\prime}$ precipitates as well as the $\gamma / \gamma^{\prime}$-eutectic almost fully into solution, alloy variants with zero Co could only be annealed with an extremely sophisticated and lengthy heat treatment. To the authors' knowledge this is obviously the reason why alloy IN713 (zero Co) is generally applied in the as-cast condition. Some trials in the present work to solution treat this alloy resulted in similar difficulties as for experimental alloys defined in this project. Even with a medium content of $4 \%$ or $6 \% \mathrm{Co}$, the full solution treatment requires a multi-step temperature/time program in order to dissolve all $\gamma^{\prime}$-precipitates and the eutectic.

The very high solution-treatment temperature of Co-free alloy modifications revealed an additional phenomenon. The $\gamma^{\prime}$-phase precipitates in an unusual odd morphology which develops already during the uppermost $20^{\circ} \mathrm{C}$ of normal cooling following the last solution-treating step. The nucleation rate is rather low in this very high temperature regime just below $\gamma^{\prime}$-solvus, and precipitate growth occurs without interaction with neighboring particles. Moreover, the diffusion rate of the $\gamma^{\prime}$-forming elements is high which leads to precipitates with dendritic morphology, also reported in [21]. Only quenching in water, which is, of course, not applicable on a technical and commercial scale, increases the number of nuclei and prevents the undesired morphology.

Nevertheless, monocrystalline alloys such as SRR99 or CMSX-6 (both have $5 \% \mathrm{Co}$ ) are also solution treated at very high temperatures and do not suffer from odd $\gamma^{\prime}$. Here, again the influence of Co on the $\gamma^{\prime}$-solvus temperature comes into play. With Co-free alloys precipitation starts immediately below the uppermost temperature step, which leads to degeneration of the $\gamma^{\prime}$-phase. For Cocontaining alloys the "window" between the highest temperature and beginning of precipitation is larger, and therefore particle growth is slower at the lower temperatures.

By fixing the Co-content at approximately $9 \%$ the alloys in principle can be solution-treated in one single temperature step and also the amount of residual $\gamma / \gamma^{\prime}$-eutectic is fairly low. Full homogenization, however, will not be achieved by such a simple treatment.
Effects of rhenium

The only significant improvement in creep strength of $12 \% \mathrm{Cr}$ nickel-base alloys can be achieved by Re-addition, because Re is a strong solid solution strengthener. Based on preliminary test results, the new DS-alloy on the basis of alloy DS-IN792 with about $12 \% \mathrm{Cr}$, alloyed with 2 to $3 \% \mathrm{Re}$, offers a temperature gain in stress-rupture strength of about $30 \mathrm{~K}$ compared to Re-free DSvariants primarily used for aero engine applications such as DS-CM247LC

In this respect it is interesting to note that the influence of Re on different alloy properties, especially on the microstructural properties, is manifold. It is not fully understood, whether the improvement of mechanical properties by Re-additions is a classical solid solution strengthening effect by individual atomic obstacles or a result of the formation of Re clusters, as reported by some authors $[22,23,24,25]$. The influence of Re on coarsening of the $\gamma^{\prime}$-microstructure during service at elevated temperatures may also play a role.

Two aspects must be discussed regarding the influence of Readditions on microstructural development. On the one hand, the kinetics of precipitate coarsening is slowed down by the presence of $\mathrm{Re}$, as it decreases the diffusion rates in the alloy. Local concentration peaks of Re are found near moving $\gamma / \gamma^{\prime}$-interfaces [26]. This so-called Re "bow wave" builds up and away-diffusion of Re-atoms becomes rate-controlling for the movement of the $\gamma / \gamma^{\prime}$ interface.

On the other hand, Re increases the lattice constant of the $\gamma$-matrix while leaving the $\gamma^{\prime}$-lattice constant nearly unchanged. This difference increases the magnitude of lattice misfit and the resulting coherency stresses between $\gamma$ - and $\gamma^{\prime}$-phase, which act as driving force for precipitate coarsening [27].

The butterfly shaped $\gamma^{\prime}$-particles found in the low Co-variants are known to be examples of a $\gamma^{\prime}$-morphology found in overaged alloys [21, 28]. In this context also the role of Re is interesting. An alloy modification with the highest Re-content in the respective test series of zero Co did not exhibit an odd $\gamma^{\prime}$-morphology. Re obviously retards $\gamma^{\prime}$-growth significantly and suppresses degenerated $\gamma^{\prime}$-particle geometry.

The most crucial aspect of Re-additions is the balance with other elements in order to avoid unacceptable phase instability. Since Re segregates strongly dendritically during solidification (partitioning coefficient $\mathrm{k}^{\mathrm{seg}}>2$ ), the precipitation of the Re-containing TCP-phase of type $P$ is concentrated in these areas (see Fig. 5). A carefully worked-out homogenization treatment can reduce or even eliminate this phase instability, which results in further significant improvement of the stress-rupture properties.

The inconsistency of $N_{v}$ theory and real TCP-precipitation behavior in Re-containing superalloys might be the consequence of the missing empirical background. According to [29], for $\operatorname{Re} a$ $N_{v}$ number of 3.66 can be expected. For the other refractory alloying elements $\mathrm{W}$ and Mo it was proved by [30] that an empirically determined $N_{v}$ number of 9.66 mirrors the experimental findings much better than the theoretically derived $N_{v}$ number of 4.66. A similar behavior of Re is likely. 
Effects of chromium/aluminum/titanium balance

As outlined in the introduction, the alloy "philosophy" for IGTblade materials is usually different from that for aero engines. Clearly, under predominantly oxidizing conditions, high $\mathrm{Al}$ alloys which form primarily an $\mathrm{Al}_{2} \mathrm{O}_{3}$ scale have best environmental resistance for both turbine types. The lower Cr-content of such alloys, in some cases as low as $2.5 \%$ as for $C M S X-10$, gives more freedom to increase other TCP-phase relevant elements such as $\mathrm{W}, \mathrm{Ta}$, or Re. In the present work it was confirmed that the oxidation attack is lowest for $\mathrm{Al}_{2} \mathrm{O}_{3}$ scale forming alloy variants compared to $\mathrm{Cr}_{2} \mathrm{O}_{3}$ scale forming alloys with less than about $4 \% \mathrm{Al}$.

If pronounced sulfate-induced hot corrosion has to be expected, the alloys should contain higher amounts of $\mathrm{Cr}$ and also of $\mathrm{Ti}$ because $\mathrm{Cr} / \mathrm{Ti}$-sulfide is the only solid sulfide type under these conditions. More than about $10 \% \mathrm{Cr}$ along with approximately $3 \% \mathrm{Ti}$ or more are typical for such materials. The surprising result in the present investigation was that also alloys with about $12 \% \mathrm{Cr}+2 \%$ Ti but higher Al-content of $5.5 \%$ or more, suffer catastrophic degradation by formation of liquid corrosion products (see Fig. 10) after an incubation period in which the alumina scale still can protect against internal sulfidation. A high Ni-content was detected in the areas in which liquid phases had formed indicating that a eutectic Ni-S composition has developed at test temperature, because the melting point of $\gamma-\mathrm{Ni}_{2} / \mathrm{Ni}_{3} \mathrm{~S}_{2}$ eutectic is $637^{\circ} \mathrm{C}$. At the corrosion front, where the eutectic composition is not yet reached, solid sulfides of the Cr/Ti-type are found (see Fig. 10 at bottom left). Possibly the sum of $12 \% \mathrm{Cr}+2 \% \mathrm{Ti}$ is not sufficient for the experimental alloys with higher Al-content to ensure as good type I hot corrosion resistance as for the lower Al-variants which were alloyed with $12 \% \mathrm{Cr}+3.5$ to $4 \% \mathrm{Ti}$.

As expected, commercial high $\mathrm{Al} /$ low $\mathrm{Cr} /$ low $\mathrm{Ti}$ aero engine alloys also tested for the sake of comparison suffer very severe catastrophic attack under the type I hot corrosion conditions simulated in the present work. Occasionally reported test results which suggest that this alloy group shows good hot corrosion resistance though the Cr- and Ti-contents are low, are probably based on too short test times within the incubation period. If such alloys are exposed to the corrosive environment in the unprotected condition for longer exposure times, e.g. after coating exhaustion or failure, rapid and presumably non-repairable attack of the blades would occur.

Non-standard elements

After the development of the second and third generation single crystal superalloys, in the meantime Re can be considered to be a standard alloying element. Nowadays alloy development focuses more on the investigation of successive generations of single crystal superalloys containing up to $5 \% \mathrm{Ru}$. Various effects of this alloying element can be found in the literature [13, 31]. Ir is also under investigation in several alloy development efforts $[12,32,33]$. Yet $\mathrm{Ru}$ and Ir can be termed non-standard elements. In this work $\mathrm{Ru}$ and Ir were added to some of the experimental alloys to investigate whether two desirable effects could be achieved: improvement of mechanical strength and phase stability.

Furthermore, it was interesting to investigate whether Ir or Ru modify the partitioning behavior of other alloying elements between $\gamma$ - and $\gamma^{\prime}$-phase and especially of Re in the same way as reported in [13] and [32]. Dislocation movement primarily takes place in the $\gamma$-matrix under service conditions. If these non- standard elements would change the partitioning behavior of Re, causing less $\operatorname{Re}$ to strengthen in the $\gamma$-phase, an addition of $\mathrm{Ru}$ or Ir could even decrease the mechanical strength, because less Re would be present in the matrix where it would contribute to improve the strength most effectively. However, no change of the partitioning behavior of $\mathrm{Re}$, caused by $\mathrm{Ru}$ - or Ir-additions, was found in the present investigation. No measurable improvement of the mechanical properties by Ru- or Ir-additions occurred either.

\section{Conclusions}

The present development leads to the following conclusions:

(1) By optimized modified alloying concepts, a new DS alloy was developed, based on the composition of IN792. This new alloy exhibits enhanced properties regarding creep strength and castability, combined with good corrosion resistance.

(2) A significant strength improvement of the class of $12 \% \mathrm{Cr}$ nickel-base alloys can be achieved by adding 2 to $3 \%$ Re. This results in an increase of temperature capability of approximately $30 \mathrm{~K}$ compared to a high-strength aero engine alloy without Re.

(3) Re-alloying leads to slight and presumably uncritical dendritic phase instability with short needle-like TCP-precipitates.

(4) By reducing the Co-content below approximately $9 \%$ the $\gamma^{\prime}$ solvus temperature increases and solution treatment becomes much more complicated. An amount of about $9 \%$ appears best.

(5) Increasing the Al-content above the limit to form an $\mathrm{Al}_{2} \mathrm{O}_{3}$ scale (i.e. above about $5 \%$ ) gives rise to catastrophic hot corrosion attack, probably promoted by a too low Ti-content.

(6) Castability of the new DS-alloy was proven by casting of large hollow IGT DS-blades in the frame of the present project. In future, new casting technologies (e.g. Liquid Metal Cooling) might even improve the excellent properties by a further refinement of microstructural features of the alloy.

\section{Acknowledgments}

The financial support of the present research project by the German Ministry of Education, Science, Research, and Technology through Grant 03N2011A, B, and C is acknowledged gratefully. Furthermore, the project benefited significantly from contributions by W. Esser and W. Hermann (Siemens Power Generation, Mülheim/Germany) and by A. Scholz and Y. Wang (Technical University, Darmstadt). The support of these colleagues is appreciated deeply. 


\section{References}

1. F. Pyczak, B. Devrient, H. Mughrabi, "The effect of different alloying elements on the thermal expansion coefficients, lattice constants and misfit of nickel-based superalloys investigated by X-ray diffraction", submitted to Superalloys 2004, 10th Int. Symp. on Superalloys, Seven Springs/PA.

2. A. Volek, R. F. Singer, R. Bürgel, J. Großmann, Y. Wang, "Influence of TCP phase formation on creep rupture life of directionally solidified nickel-base superalloys", to be published in Metallurgical and Materials Transactions A.

3. R. Darolia, D. F. Lahrmann, R. D. Field, "Formation of Topologically Closed Packed Phases in Nickel Base Single Crystal Superalloys", in S. Reichman et al. (eds.), Superalloys 1988, Proc. 6th Int. Symp. on Superalloys, Seven Springs/PA, The Minerals, Metals and Materials Society, Warrendale/PA, 1988, 255264

4. F., Pyczak, H. Biermann, H. Mughrabi, A. Volek, R. F. Singer, "CBED-measurement of residual internal strains in the neighbourhood of TCP-Phases in Ni-base superalloys", in T. M. Pollock et al. (eds.), Superalloys 2000, Proc. 9th Int. Symp. on Superalloys, Seven Springs/PA, The Metallurgical Society of AIME, Warrendale/PA, 2000, 367-376.

5. L. R. Woodyatt, C. T. Sims, H. J. Beattie, "Prediction of sigma-type phase occurence from compositions in austenitic Superalloys", T. Metall. Soc. AIME 236 (1966) 519-527.

6. A. Volek, F. Pyczak, R. F. Singer, H. Mughrabi, "Partitioning of Re between $\gamma$ and $\gamma$ ' phase in nickel-base superalloys", to be published in Scripta Materialia.

7. H. Kriege, J. M. Baris, "The Chemical Partitioning of Elements in $\gamma$ ' Separated from Precipitation-Hardened, HighTemperature Nickel-Base Alloys", Transactions of the ASM, 62 (1969) 62, 195-200.

8. D. Blavette, P. Caron, T. Khan, "An Atom Probe Investigation of the role of Rhenium Additions in Improving Creep Resistance of Ni-base Superalloys", in D. N. Duhl et al. (eds.), Superalloys 1988, Proc. 6th Int. Symp. on Superalloys, Seven Springs/PA, The Metallurgical Society of AIME, Warrendale/PA, 305-314.

9. G. Schumacher, H.-G. Esser, W. Miekeley, G. Frohberg, H. Wever, R.P. Wahi, "Lattice Parameters of $\gamma$ and $\gamma$ ' Phases in Superalloy SC16 in Unconstrained Condition", Z. Metallkde., 89 (1998), 661-665.

10. C. Schulze, M. Feller-Kniepmeier, "Transmission Electron Microscopy of Phase Composition and Lattice Misfit in the ReContaining Nickel-Base Superalloy CMSX-10", Mat. Sci. Engg., A281 (2000) 204-212.

11. C. Schulze, M. Feller-Kniepmeier, "Phase Compositions and Lattice Misfit in CMSX-11B Partition Coefficients in Single Crystal Nickelbase Superalloys", Scripta Mat., 44 (2001) 731-736.
12. T. Yokokawa, M. Osawa, K. Nishida, T. Kobayashi, Y. Koizumi, H. Harada, "Partitioning behavior of platinum group metals on the $\gamma$ - and $\gamma$ '-phases of Ni-base superalloys at high temperatures", Scripta Mat., 49 (2003) 1041-1046.

13. K. O'Hara, W.S. Walston, E.W. Ross, R. Darolia, "NickelBase Superalloy and Article", United States Patent Application, Patent No. 5.482.789, Application No. 176.613, 1996.

14. C.H. Lund, M.J. Woulds, J. Hockin, "Cobalt and Sigma: Participant, Spectator, or Referee?", in E.G. Richards et al. (eds.), Proc. 1st Int. Symp. on Structural Stability in Superalloys, Joint Committees of ASTM, ASME, ASM, and AIME, Seven Springs/PA, $1968,25-46$.

15. H. Murakami, T. Yamagata, H. Harada, M. Yamazaki, "The influence of $\mathrm{Co}$ on creep deformation anisotropy in Ni-base single crystal superalloys at intermediate temperatures", Mat. Sci. Engg., A223 (1997), 54-58.

16. M.V. Nathal, R.D. Maier, L.J. Ebert, "The Influence of Cobalt on the Microstructure of the Nickel-Base Superalloy MARM247", Met. Trans. A, 13A(1982), 1775-1783.

17. M.V. Nathal, L.J. Ebert, "The Influence of Cobalt, Tantalum, and Tungsten on the Microstructure of Single Crystal Nickel-Base Superalloys", Met. Trans. A, 16A(1985), 1849-1862.

18. M.V. Nathal, L.J. Ebert, "The Influence of Cobalt, Tantalum, and Tungsten on the Elevated Temperature Mechanical Properties of Single Crystal Nickel-Base Superalloys", Met. Trans. A, 16A(1985), 1863-1870.

19. K. Matsugi, Y. Murata, M. Morinaga, N. Yukawa, "Realistic Advancement for Nickel-Based Single Crystal Superalloys by the d-Electrons Concept", in S. D. Antolovich et al. (eds.), Superalloys 1992, Proc. 7th Int. Symp. on Superalloys, The Minerals, Metals and Materials Society, Warrendale/PA, 1992, 307-316.

20. N. Yukawa et al., "High Performance Single Crystal Superalloys Developed by the d-Electrons Concept", in S. Reichman et al. (eds.), Superalloys 1988, Proc. 6th Int. Symp. on Superalloys, Seven Springs/PA, The Minerals, Metals \& Materials Soc., Warrendale/Pa., 1988, 225-234.

21. T. Grosdidier, A. Hazotte, A. Simon, "Precipitation and Dissolution Processes in $\gamma / \gamma^{\prime}$ Single Crystal Nickel-Based Superalloys", Mat. Sci. Engg., A256 (1998), 183-196.

22. D. Blavette, P. Caron, T. Khan, "An Atom Probe Investigation of the Role of Rhenium Additions in Improving Creep Resistance of Ni-base Superalloys", Scripta Metall., 20 (1986) 13951400 .

23. N. Wanderka, U. Glatzel, "Chemical composition measurements of a nickel-base superalloy by atom probe field ion microscopy”, Mat. Sci. Engg., A203 (1995) 69-74. 
24. J. Rüsing, N. Wanderka, U. Czubayko, V. Naundorf, D. Mukherji, J. Rösler, "Rhenium distribution in the matrix and near the particle-matrix interface in a model Ni-Al-Ta-Re-superalloy", Scripta Mat., 46 (2002) 235-240.

25. R.W. Broomfield et al., "Development and Turbine Engine Performance of Three Advanced Rhenium Containing Superalloys for Single Crystal and Directionally Solidified Blades and Vanes", ASME (IGTI) Turbo Expo '97, Orlando/FL., USA, 1997.

26. P.J. Warren, A. Cerezo, G.D.W. Smith, "An atom probe study of the distribution of rhenium in a nickel-based superalloy", Mat. Sci. Engg., A250 (1998) 88-92.

27. F. Pyczak, B. Devrient, F.C. Neuner, H. Mughrabi, "The influence of different alloying elements on the development of the $\gamma^{\prime}$-structure of nickel-base superalloys during high-temperature annealing and deformation", to be published.

28. M. Doi, T. Miyazaki, T. Wakatsuki, "The effect of elastic interaction energy on the morphology of the $\gamma^{\prime}$-precipitates in nickel-based superalloys", Mat. Sci. Engg., 67 (1984) 247-253.

29. L. Pauling, "The nature of the interatomic forces in metals", Physical Reviews, 54 (1938), 899-904.

30. J. R. Mihalisin, C. G. Bieber, R. T. Grant, "Sigma - its occurence, effect, and control in Nickel-base Superalloys", Trans. Met. Soc. of AIME, 242 (1968) 12, 2399-2414.

31. P. Caron, "High $\gamma$ ' Solvus New Generation Nickel-Based Superalloys for Single Crystal Turbine Blade Applications", in T. M. Pollock et al. (eds.), Superalloys 2000, Proc. 9th Int. Symp. on Superalloys, Seven Springs/PA, The Metallurgical Society of AIME, Warrendale/PA, 2000, 737-746.

32. T. Kobayashi, Y. Koizumi, S. Nakazawa, T. Yamagata, H. Harada, "Design of High Rhenium Containing Single Crystal Superalloys with Balanced Intermediate and High Temperature Creep Strengths", in A. Strang et al. (eds.), Proc. 4th International Charles Parson Turbine Conference, The Institute of Materials, 1997, 766-773.

33. H. Murakami, Y. Koizumi, T. Yokokawa, Y. YamabeMitarai, T. Yamagata, H. Harada, "Atom Probe Microanalysis of Ir-bearing Ni-based Superalloys”, Mat. Sci. Engg., A250 (1998), 109-114. 